Araștırma Makalesi - Gönderim Tarihi: 29.09.2018 Kabul Tarihi: 20.12.2018

\title{
Dijital Gazetelerin Sosyal Medya Stratejileri ve Sosyal Medyanın Haber Okunurluğuna Etkisi ${ }^{1}$
}

\author{
Ilke Atik Tașkıran²
}

Öz

Bu çalışmada sosyal medyanın dijital gazeteler açısından önemini ortaya çıkarmak amacıyla, dijital gazetelerin sosyal medya stratejilerinin neler olduğu ve sosyal medyanın haber okunurluğuna etkisinin ne olduğu sorularına cevap aranmıştır. Bu amaçla, araştırma Google Analytics raporlarına erişime olanak veren T24, Korhaber ve Rotahaber adlı üç dijital gazete ile yürütülmüştür. Araştırmanın sonucunda, gazetelerin sosyal ağlardaki kullanıcıyı çekmek için sitelerinde özel paylaşım formatlarına yer verdikleri, paylaşımlarında ası amacın sitenin trafiğini arttırmak ve oluşturulan gündem haberlerini güçlendirmek olduğu belirlenmiştir. Paylaşımlarında saat dilimleri değişikliğinin, okunan haber türüne bir etkisi olmadığı belirlenmiştir. Facebook ve Twitter olarak incelenen iki ağda, gazetelerin farklı haberleri ön plana çıkarttıkları görülmüştür. Sosyal medyanın dijital gazetelerdeki haber okunurluğuna etkisine bakıldığında ise; her gazeteye ait farklı yüzdeler elde edilmiştir. Bunun sonucunda her gazete için belli bir oranda etkisi olduğu ancak bu etkinin beklenenden az olduğu görülmüştür. Türkiye'deki dijital gazeteler için Twitter'ın okunmaya etkisinin daha yoğun olduğu tespit edilmiştir.

Anahtar Kelimeler: haber okunurluğu, sosyal medya, dijital gazete

Atıf: Atik Tașkıran, IIke. (2018). Dijital Gazetelerin Sosyal Medya Stratejileri ve Sosyal Medyanın Haber Okunurluğuna Etkisi. Akdeniz Üniversitesi Illetișim Fakültesi Dergisi, (AKiL) Aralık (30) s. 218-240

1 Bu çalışma Prof. Dr. Haluk Kazım Geray’ın danışmanlığında İlke Atik Taşkıran tarafından tamamlanan yüksek lisans tez çalışmasından üretilmiştir.

2 Doktora Öğrencisi, Ankara Üniversitesi, İletişim Fakültesi Gazetecilik Ana Bilim Dalı, ilkeatik@gmail.com 


\title{
The Social Media Strategies of Digital Newspapers and the Influence of Social Media on the Number of the News Read
}

\begin{abstract}
In this study, it is aimed to reveal the importance of social media in terms of digital newspapers. With this aim, the social media strategies of digital newspapers and the influence of social media on the number of the news read by the users are questioned. The research was carried out with the newspapers T24, Korhaber, and Rotahaber that enable the access of the reports of Google Analytics. Finally, this research demonstrates that the newspapers employ special sharing formats to attract the users. The main objectives of the posts they share are to both increase the number of the visitors of the site and strengthen the news of the agenda that is set. It was also figured out that the changes of time zone do not have any effect on the sort of the news read in the posts shared. It was observed that the newspapers could feature different news on both Facebook and Twitter. When the influence of the social media on the number of the news read in the digital newspapers was scrutinized, various percentages were obtained for every newspaper read. Finally, it was observed that social media influences digital newspapers to a certain extent, but this effect is less than expected. The results indicated that Twitter has more influence on the rate of the digital newspapers read in Turkey.
\end{abstract}

Keywords: internet, news, social media, digital newspaper 


\title{
Giriș
}

\begin{abstract}
$\sim_{3}$ ağdaş teknolojiler ile birlikte gazetecilik ve haber alma koşulları büyük oranda değişime uğramıştır. Bu yaşanan değişimler sonucunda gerek yazılı basın, gerekse görsel medya, internet gazeteciliğine kayıtsız kalamamışlardır. Bunların yarึ sıra yazılı veya görsel basında yer almayan, doğrudan internet üzerinde, kişisel yatırım ve becerilerle kurulan, arkasında büyük medya gruplarının yerine şahısların olduğu dijital gazeteler de internet haberciliğinde önemli bir yer edinmişlerdir.
\end{abstract}

Dijital gazetelerin adlarını duyurabilmeleri, binlerce alternatif arasında öne çıkabilmeleri ve sabit bir okuyucu kitlesi edinebilmeleri için, internet ortamında reklam, arama optimizasyonu, sosyal medya gibi araçlardan yardım alma zorunlulukları doğmuştur.

Bu çalışmada yardımcı araçlardan sosyal medya platformlarına değinilerek, sosyal medyanın dijital gazeteler açısından önemi ortaya çıkarılmak istenmiştir. Bu amaçla yapılan çalışmanın kuramsal kısmında, öncelikle yeni iletişim teknolojileriyle medyada yaşanan değişimler, yeni medya ortamında değişen gazetecilik ve internet gazeteciliği konularına değinilecektir. Ardından sosyal medyanın gazetecilikte kullanımı ele alınarak; dünyada sosyal medyanın haber okunurluğuna etkisini araştıran çeşitli enstitülerin raporlarına ayrıntılı olarak yer verilecek, Türkiye'de sosyal medyadan haber okunmasına ilişkin yapılan araştırmalar konu edilecektir. Araştırma bölümünde ise araştırma kapsamındaki dijital gazetelerden alınan verilerden elde edilen sonuçlar değerlendirilecek ve dijital gazeteler için daha iyi sosyal medya kullanımına yönelik öneriler geliştirilecektir.

\section{Yeni Illetișim Teknolojileri ile Dönüșen Medya ve Gazetecilik}

Çağdaş teknolojik gelişmeler ile geleneksel iletişim araçları yerini, zamansal ve mekansal sınırların kalktığı, enformasyon aktarımlarını bir ağ içinde bütünleştirmeyi mümkün kılan sayısal tabanlı iletişim araçlarına bırakmıştır.

Yeni iletişim teknolojileriyle yaşanan değişiminden en çok etkilenen sektörlerden biri de medya sektörü olmuştur. Gazeteler, haber yapma koşulları, okurlar, hatta gazetecilik mesleği bile bu teknolojilerle büyük dönüşümler geçirmiştir. Bu dönüşümün en büyük belirleyeni 'internet' olmuştur. Internet ortamında hem okuyucunun aktif olabilmesi, hem de haberlerin anlık olarak, ertesi sabah gazete baskısı beklemeden sunulabilmesi büyük değişimleri beraberinde getirmiştir.

Okuyucu evinde pasif gazete okuyup, sosyal ortamındaki arkadaşlarıyla haber yorumlayan kişi olmaktan çıkıp, içerik üreten, her habere anında yorum yapabilen, sosyal medya ortamlarında tanımadığı insanlarla gündemi tartışan, yeri geldiğinde tepkileri veya protestolarıyla gündemi oluşturan aktif okuyucu konumuna geçmiştir.

Yeni iletişim ortamları geliştikçe içerikler, haberlerin verilişi, sunumu, haber yazmanın, yaratmanın kuralları da değişerek farklılaşmıştır. 


\begin{abstract}
"Kişiye özel haberler, eşzamansızlık, her an her yerde ulaşabilme gibi internetle birlikte gelen "nimetler"; yeni okurun çoklu ortam tercihi, haber ve yorumlama sürecine katılım isteği gibi geçirdiği değişimler; cep telefonlarına kısa mesaj halinde düsen, bilgisayar ekranından izlenen haberler derken değișen ortama, okura uymaya çalışan haber içeriklerinin belli başlı özellikleri de değişmiştir. Artık tüm kitleye göre değil, kullanılan mecraya ve bu mecranın kullanıcısına göre içerik üretilmektedir ya da üretilecektir" (Çakır, 2009: 57-59).
\end{abstract}

Bununla birlikte, GMSC 2016 verilerine göre (Türkiye'de mobil kullanıcı araştırmasının sonuçlarını yayımlıyoruz, 2016); Türkiye'deki mobil kullanıcıların yüzde 59'unun haberleri okumak için cep telefonunu kullandığı düşünüldüğünde, haber içeriklerinin cep telefonları formatlarına uygun olması gerekliliği de doğmuştur. Bu durumda haberlerin görselleri, uzunlukları ve hatta görüntülerinin daha özet ve pratik sunulması gerekmiştir.

Yeni iletişim teknolojilerinin medyaya getirdiği en önemli yeniliklerden biri de, web analiz araçları yardımıyla okuyucunun ne istediğinin, kim olduğunun (cinsiyet, yaş, hobi vb.) ve hangi haberleri ne kadar okuduğunun bilinmesi olmuştur. Medya şirketleri veya gazeteciler okuyucuları tanımak ve onlara göre içeriklerini düzenleme şansına sahip olmuşlardır. Okuyucu ve haber içeriklerinde yaşanan değişimlerin yanı sıra, bir diğer değişim de medya şirketlerinin yapısında yaşanmıştır. Illetişim sektöründe yaşanan yöndeşmeler ile dev medya grupları ortaya çıkmıştır.

Pavlik, gazetecilikte yaşanan değişimi açıklarken, yeni iletişim teknolojileri ile "bağlamlı gazetecilik" olarak nitelendirilebilecek yeni bir gazetecilik biçiminin doğduğunu belirtmiştir (2013:11). Pavlik'e göre, habere iletişim yöntemlerinin genişliği, hiper medya, yüksek okuyucu kitlesinin katılımı, dinamik içerik, uyarlama gibi ayırt edici özellikleri olan bağlamlı gazetecilik, internet gibi yeni iletişim teknolojilerinin gazeteciliğin dört aşamasını değiştirmesiyle ortaya çıkmıştır (Pavlik, 2013:11). Bunlardan ilki haber içeriğinin doğasının değişmesidir. İkincisi, gazetecilerin işlerini yapma şeklinin değişmesi; üçüncüsü, basın odası ve basın endüstrisinin yapısının değișime uğramış olmasıdır. Dördüncüsü ise yeni medyanın; haber örgütleri, gazeteciler, okuyucular, kaynaklar, rakipler, reklamcılar ve hükümetler arasındaki ilişkileri yeniden düzenlemesidir (Pavlik, 2013).

Gazetecilerin kaynak bulmada kullandığı teknolojilerle haber yapımları kolaylaşmış, klasik muhabirlik anlayışını değişerek masa başı muhabirlik kavramı doğmuştur. Röportajlar bile elektronik posta ortamında soruların gönderilmesiyle yapılır olmuştur.

"Günümüzde iyi bir gazeteci olabilmek için sadece gazetecilik mesleğini öğrenmek yeterli değildir, aynı zamanda iyi bir teknoloji kullanıcısı olması gerekmektedir. Özellikle bilgisayar bilgisi gazeteci için çok önemli bir gereklilik haline gelmiştir. Ayrıca dijital fotoğraf makinesi, tarayıcı (scanner), dijital kamera, yazıcı, hatta cep telefonunun yanında işiyle ilgili çeşitli yazılım ve programlarla, internetin çeşitli araçlarını; e-posta, web, dosya transferi, haber grupları, mail listeleri, forumlar, ses ve görüntü akışı gibi detayları tanıyıp, kullanabilmelidir" (Toruk, 2008: 325). 
Yeni iletişim teknolojileri beraberinde, yeni gazetecilik türleri de doğurmuştur. Yurttaş gazeteciliği, veri gazeteciliği, robot gazeteciliği, internet gazeteciliği gibi yeni gelișen gazetecilik modelleri her geçen gün geleneksel gazetecilik kavramının önüne geçmektedir. Artık haber yapma veya haberi yaymak için çok geniş platformlar ve iletişim teknolojileri mevcuttur.

\section{1. İnternet Gazeteciliği}

İnternet gazeteciliği kavramı günümüzde çok sık kullanılan bir kavram haline gelmiştir. "Haber gruplarının kendi abonelerinin elektronik postalarına gönderdiği iletiler ile başlayan elektronik iletişim örnekleri, internet üzerinde kullanılan farklı donanım ve yazılım uygulamalarının da gelişmesiyle birlikte internet gazeteciliğini ya da diğer bir deyişle sanal gazeteciliği doğurmuştur." (Kırçıl ve Karagüler).

“İnternet gazeteciliği 1995 yılında ABD’de sekiz büyük gazetenin (The Washington Post, New York Times) çevrimiçi olarak, baskıya hazır gazete sayfalarını anında okuyucuların bilgisayarlarına aktarma amacıyla bir araya gelmesiyle kurumsal düzeyde başlamıştır" (Kırçıl ve Karagüler, 2003: 2). Ardından "The Daily Telegraph kendi içeriğini internet üzerinden ulaşılabilir yapan ilk İngiliz ulusal gazetesi olmuştur" (Rudin\&lbbotson, 2003: 95). Bu gelişmelerin üzerine birçok ülkede gazetelerin (Der Spiegel, China Business Journal, USA Today gibi) sanal yayınları yapılmaya başlanmıştır.

Geleneksel yayın yapmayan ve yayına doğrudan internet ortamında başlayan dijital haber siteleri ortaya çıkmıştır. Huffington Post, bu kategorinin iyi bir örneğidir. 2005 yılında internet aracılığıyla doğan Huffington Post, Aralık 2016 verilerine göre, dünyada en çok okunan haber siteleri arasında üçüncü sıraya yerleşmiş ve aylık tekil ziyaretçi sayısı 110.000.000'a ulaşmıştır (Top 15 Most Popular News Websites, 2016).

Bununla birlikte Buzzfeed gibi dijital gazetelerin oluşturduğu yeni modeller de internet haberciliğinde adından söz ettirmektedir. Kalsın'a göre kendi özgün haberlerini de barındıran bir haber-blog sitesi olan Buzzfeed, eğlenceli bir internet haberciliği çeşidi benimsemiştir. Kullanıcıya seçme imkanı veren Buzzfeed, içeriği yeni dinamikleri kullanarak okuyucuya sunmaktadır (Kalsın, 2016: 79).

Türkiye'de internet yayıncılığının doğuşu, 19 Temmuz 1995'te çevrimiçi yayıncılığa adım atan Aktüel dergisinin, kendi internet sayfasını açmasıyla başlamıştır. Ardından Ekim ayında Leman Dergisi internetten yayın yapmaya başlamıştır. Gazeteler arasından ise Zaman Gazetesi 2 Aralık 1995 tarihinde ilk çevrimiçi yayıncılık yapan site olmuştur. Gazetelerindeki haberleri ve köşe yazılarını internete taşıyan gazetenin ardından, Milliyet gazetesi, 27 Kasım 1996'da gazetenin tamamını internet ortamında veren ilk günlük gazete olmuştur. Bunun arkasından gelen gazeteler Hürriyet ve Sabah gazeteleri olmuştur. Yıllar içinde genişleyen bu listeye bugün bakıldığında internet üzerinden yayın yapmayan ulusal ölçekli gazete kalmadığı görülmektedir. Gazeteler başlangıçta internet sitelerinde o günkü sayılarına yer verirken, şu an gazetelerin siteleri 24 saat güncellenen platformlara dönüşmüştür. Basılı gazetelerin içeriğini, internetten okuyucuya zaten sunulan içerik oluşturmaktadır. 
“Türkiye'nin ilk dijital haber sitesi ise 25 Ocak 1996'da yayın hayatına başlayan XN olmuştur. XN'de gazetelerden taranan günlük seçme haber ve köşe yazılarına yer verilmiştir, fakat www.xn.com sitesi çok geçmeden yayınına son vermiştir. 17 Aralık 1997'de Türkiye'nin en büyük servis sağlayıcılarından biri olan Superonline'ın internet sitesine bağlı olarak kurulan Net-Haber, Anadolu Ajansı ve Reuters'in haberlerini ziyaretçilerine ulaştırmıştır. İçeriği tamamen kendine özgü olan ve bağımsız yayıncılık yapan ilk site ise, gazeteci Ahmet Tezcan'ın kurduğu www.dorduncukuvvetmedya.com' dur" (Kalsın, 2016:78).

Özellikle ülkede yaşanan ekonomik krizinde etkisiyle 2000-2001 yıllarında internet haberciliğinde Türkiye'de büyük bir patlama yaşanmıştır. İşsiz kalan gazeteciler kendilerine haber yapma, yazılarını yazma, seslerini duyurma aracı olarak kurulum maliyeti düşük olan internet haberciliğini tercih etmiş ve birçok dijital gazete doğmuştur. Kimi kendi şahsi adına, kimi ulusal gazete formatında, sadece ekonomi, sadece siyaset gibi birçok yayın tarzını içeren dijital gazetelerin sayısı, basılı gazetelerin sayısını fazlasıyla katlamıştır.

Binlerce dijital haber sitesi arasından ajans haberlerini vermelerinin yanı sıra orijinal içerik üreten, tematik konulara yer veren ya da yeni teknolojiler kullanarak farklılaşan siteler okuyucular tarafından daha çok tercih edilerek öne çıkmıştır. Bu siteler arasında siyasi özgün içerikleriyle Oda.tv, özgün köşe yazarlarıyla T24, yurttaş haberciliğini ilke edinmesiyle Bianet, muhalif duruşuyla Diken gibi dijital gazeteler, geleneksel gazetelerin arasından öne çıkmayı başararak büyük bir okuyucu kitlesine ulaşmıştır.

\section{Sosyal Medya ve Gazetecilik}

Sosyal medya kavramı, sadece medya ile ilgili bir kavram değil; kullanıcı tabanlı içeriğiyle, Web 2.0 teknolojilerinin kullanımıyla ve geleneksel medyadan farkıyla birçok boyutu olan bütünleşik bir kavramdır. Bununla birlikte "sosyal medya, basit bir anlatımla insanların sosyalleşmek için kullandıkları bir medya türüdür” (Safko, 2010: 3).

Blackshaw ve Nazzaro (2004) sosyal medyayı, "diğer bireyleri ürünler, markalar, kişiler ve konular hakkında bilgilendirmek amacıyla tüketiciler tarafından yaratılan, başlatılan, dağıtılan ve kullanılan yeni çevrimiçi bilgi kaynakları" olarak tanımlamışlardır. Buna göre "sosyal medya, çeşitli çevrimiçi blogları, tüketici forumlarını, işletme sponsorlu tartışma panelleri ve sohbet odalarını, tüketiciden-tüketiciye e-postaları, tüketici ürün veya hizmet puanlama sitelerini, tartışma panelleri ve forumlarını, moblogları (dijital ses, görüntü film veya fotoğraflar) ve sosyal ağ sitelerini kapsayan bir iletişim aracı olarak konumlandırılmaktadır" (Mangold ve Faulds, 2009: 357-365).

"Sosyal medyanın ortaya çıkışı 1979 yılında kullanıcılarına mesajlaşma imkanı sunan bir tartışma platformu olan, Usenet ile başlamaktadır.. Günümüzdeki anlamındaki sosyal medya ise 1989 yılında Bruce ve Susan Abelson tarafından kurulan Open Diary Web sitesi ile ortaya çıkmıştır. Çevrimiçi günlük yazan kişileri bir araya getiren sitenin açılmasından sonra aynı yıl "Weblog" kavramı ortaya çıkmış ve blog kavramı 
oluşmuştur. Daha sonra MySpace (2003) ve Facebook (2004) gibi sosyal ağ siteleri kurularak sosyal medya oluşma aşaması gelişmiştir" (Kaplan ve Haenlein, 2009: 60).

Yüksel'e göre, sosyal medya diğer iletişim araçlarından; üretim sürecine toplumu dahil etmesiyle farklılaşmıştır. Sosyal medya ile bugüne kadar bilginin ve haberin tüketicisi olan toplum, üretici konumuna da yükselmiştir (2014: 119).

İnternet üzerinden çeşitli biçimlerde bilgi paylaşma olanağı verebilen, birçok interaktif araç bileşiminden oluşan sosyal medya, gazeteciler için "kaynak bulmak, kamuoyunun nabzını tutmak, haber üretmek gibi çeşitli gazetecilik faaliyetlerini yerine getirmede" hayati bir rol almaya başlamıştır (Acharya vd., 2012'den aktaran Kurt, 2014: 823).

Beckett sosyal medya ile gazetecilik ilişkisini değerlendirirken, geleneksel medyanın bugünün tüketicilerinin isteklerini farkına varması gerektiğine dikkat çekerek, bugünün yeni tüketicilerinin bilgiye daha eleştirel yaklaştıklarını bu yüzden de, gazetecilik için artık bilinen haberleşme araçlarının ötesinde siber alemdeki izleyicilere de ulaşmak gerektiğine dikkat çekmiştir (2008: 4).

Bununla birlikte okur kitleleriyle doğrudan iletişime ve etkileşime geçebilmek gazetecilerin çalıştığı mecralardan ayrılarak bireysel marka olarak ön plana çıkmalarını sağlamaktadır. Sosyal medyayı etkin olarak kullanan ve okuyucusu (takipçileri) ile birebir etkileşime geçen gazetecilerin takipçi sayılarında gözle görünür bir farklılık oluşurken; bu isimlerin sosyal medyadaki aktiflikleri, isimlerini daima güncel tutmaktadır.

Gazetecilerin sosyal medya kullanımlarında yurttaşlar kadar özgür olup olmadığı bir tartışma konusudur. Birçok medya kuruluşu tarafından çalışanlarına sosyal medya kullanım ilkelerini uygulama zorunluluğu getirmiştir. Bu ilkelere uymayanlara işten çıkarılmaya varıncaya dek çeşitli yaptırımlar uygulanmaktadır. Bu bağlamda çalışan gazetecilerin sosyal medya kullanımlarında özgürlüklerinin kısıtlandığı bir gerçektir.

Dünyada olduğu gibi Türkiye'de de birçok medya kuruluşunda, benzer kısıtlamalar uygulanmaktadır. Örneğin, AA haber ajansı sosyal medya politikalarına göre çalışanlar, siyasi görüşlerini sosyal medya hesaplarından belli edememekte veya haber niteliği olan bilgiyi kurumlarına haber vermeden hesaplarında paylaşamamaktadırlar.

Bunun yanı sıra haber kaynağı olarak kullanılan sosyal medya platformları, gazeteciler için sağladığı kolaylıklarla beraber, çeşitli riskler barındırabilmektedir. Özellikle toplumsal olaylarda yoğun bilgi akışının yaşandığı sosyal medyada, doğru haber kadar, abartılmış veya tamamen yanlış olan birçok enformasyon akışı yaşanmaktadır. Teyit edilmeden yapılan her haber, toplumsal infiale veya gazeteciye duyulan güvenin azalmasına neden olabilmektedir.

Gazetecilik mesleğini profesyonel biçimde yapanların sosyal medya kullanım alışkanlıklarını ve bu yeni mecra ile olan ilişkilerini belirlemek için Ege Üniversitesi'nden Hanifi Kurt tarafından yapılan çalışmada, gazetecilerin yeni iletişim ortamı olarak 
sosyal medya uygulamalarını kullanma konusunda istekli ve talepkar oldukları ifade edilmektedir (Kurt, 2014: 833). Kurt'un çalışmasına göre, gazeteciler sosyal medyayı önce özel yaşamlarında kullanmış, daha sonra mesleki pratiklerinin bir parçası haline getirmişlerdir. Çalışmada gazeteciler arasında en fazla Twitter, Facebook ve Youtube uygulamalarının kullanıldığına dikkat çekilmiştir. Türkiye'deki gazetecilerin sosyal medyayı belirgin biçimde "neler olup bittiğini takip ve var olan haberleri güncellemek" amacıyla kullandıklarının da altı çizilmiştir.

\subsection{Habere Erișim Ortamı Olarak Sosyal Medya}

Sosyal ağların neredeyse birçok ülkenin nüfusundan fazla olan kullanıcı sayıları, sosyal medyayı bulunmaz bir reklam ve pazarlama mecrası yaparken, bu kadar kullanıcının sosyal medyada ne yaptığı birçok araştırmanın konusu olmuştur. Dijital platformdaki gazeteler için de, kullanıcıların haberlerini okumasında sosyal medyanın ne kadar etkisi olduğu önemli bir bilgi niteliğindedir. Gazeteler buradaki rakamlara göre, sosyal medya kullanımlarını şekillendirmek durumundadırlar.

Oxford Üniversitesi'ne bağlı Reuters Enstitüsü’nün 26 ülke için yaptığı Dijital Haber Raporu 2016 başlıklı araştırmasında, ankete katılanların yüzde 51'inin sosyal medyayı haftalık haber kaynağı olarak kullandığı tespit edilmiştir (Dijital Haber Raporu, 2016). Bu oranın yaklaşık yüzde 12'sinin ana kaynak olarak sosyal medyayı kullandığı belirtilmiştir. Bununla birlikte raporda Facebook'un en önemli paylaşım ağı olduğunun da altı çizilmiştir.

Burada dijital gazeteleri ilgilendiren bilgi, sitelerine aldığı trafiğin ne kadarının sosyal medyadan geldiğidir. Nic Newman tarafından raporda dikkat çekilen önemli bir ayrıntı, insanların haberleri sosyal medyadaki geri dönüşlerden, yorumlardan, tartışmalardan takip ettiği ve dijital ortamda siteye giderek haberin orijinalini okumaya daha az intiyaç duyduğudur. Bu durumda kullanıcı haberi sosyal medyadan öğrenmiş olsa da siteye trafik sağlamamaktadır.

Columbia Üniversitesi ve Fransız Ulusal Enstitüsü tarafından insanların sosyal medya platformlarındaki paylaşım alışkanlıklarını inceleyen bir diğer araştırmada da sosyal medyada haberlerin okunmadan paylaşıldığının altı çizilmiştir. CNN, The New York Times, The Huffington Post, BBC ve Fox News'un sitelerindeki haberlerin sosyal medyadaki paylaşımlarının bir ay boyunca takip edildiği araştırmada, sosyal medyada binlerce kez paylaşılan linklerin yüzde 59'unun kullanıcılar tarafından tıklanmadan paylaşıldığı tespit edilmiştir (New Study Highlights Power of Crowd to Transmit News on Twitter, 2016). Arnaud Legout'nun çalışma ile ilgili yaptığı yazılı açıklamaya göre; sosyal medya kullanıcıları, bir haber makalesini okumaktansa onu paylaşmayı tercih etmektedir:

"Insanların bir haberi okumak yerine paylaşmayı tercih etmeleri tipik bir modern bilgi tüketimi davranışı. İnsanlar; bir fikri o fikrin özetine, hatta özetinin özetine bakarak, daha derinlere inmek için herhangi bir efor sarf etmeden oluşturuyor." Araştırmacıların 
ulaştıkları sonuçlara göre sosyal medyada haberlerin sunuluş tarzı, kullanıcıların o habere tıklayıp tıklamamasını belirleyen en önemli etken. Araştırmacılar, sosyal medyadaki paylaşım alışkanlıklarının internetteki trendleri anlamlandırmada yardımcı olabileceğini düşünüyor (Sosyal Medyada Haberler Okunmadan Paylaşılıyor, 2017 ).

Dijital yayıncıların çevrimiçi içerik ölçümleme platformlarından biri olan Parse.ly Network tarafından Ocak-Mart 2016 için 'The Authority Report' adıyla sunulan raporda ise Twitter'ın haber siteleri için önemi konu edilmiştir (Does Twitter Matter for News Sites, 2016). Rapora göre Twitter dijital yayıncılara ortalama yüzde 8,5'lik bir trafik sağlamaktadır.

Yine Parse.ly tarafından hazırlanan Ocak-Ekim 2015 Authority Report'da ise dijital platformda yer alan 2015'in en çok ses getiren haberleri için okuyucu trafiğinin nereden geldiği araştırılmıştır (Understanding Traffic Patrterns from the Top News Topics of $2015,2015)$. Raporda gelen trafik, en çok trafik sağlayan iki büyük kaynak olarak arama motorları ve sosyal medya trafikleri üzerinden incelenmiştir. Arama kaynakları olarak Google, Yahoo vb. alınırken, sosyal kaynak olarak Facebook ve Twitter'ı alınmıştır. Raporda sonuç olarak, aslında konuya göre insanların tercihlerinin değiştiği ve burada sosyal medya veya arama motorunun önemini açıklamaktan ziyade maneviyatın ve psikolojinin medya trafiğinde değişikliğe yol açtığını söylenmektedir.

Yeni medya üzerine değinen bir diğer araştırma olan ve Pew Research Center tarafından yayınlanan 'State of the News Media 2016' adlı raporda Amerikalı yetişkinlerin büyük çoğunluğunun, şu anda haberleri daha çok sosyal medya üzerinden aldığı ve yayıncıların, bu yönelim karşısında daha fazla sosyal medya iletişimine yanıt verebilecek şekilde ayarlamalar ve uygulamalar için çaba gösterdikleri belirtilmiştir. Raporda, dijital teknoloji ortamında doğup yetişmiş kesimleri çekebilmek, kavrayabilmek için, haber sitelerinin bu talepleri karşılayacak şekilde yapılanmalarının doğru bir yaklaşım olduğu belirtilirken sadece Facebook, Twitter değil, bu alana her gün yenisi eklenen Snapchat, ve İnstagram da buna dahil tutulmuştur. Pew Araştırma Merkezi'nin araştırmasının sonuçlarına göre, haber edinme açısından sosyal medya kullanımı, televizyonun ardından ikinci sırada yer almaktadır

Araştırma sonuçlarına göre, Amerikalı yetişkinler yaklaşık olarak yüzde 38 sıklıkla, haberleri dijital kaynaklar, haber siteleri (yüzde 28) ve sosyal paylaşım ağları (yüzde 18) üzerinden almaktadır. Haber alma yolları, sıklıkla televizyon (yüzde 57) olmakla birlikte, radyo (yüzde 25) ve gazeteler de (yüzde 20) önemli yer tutmaktadır.

Raporda bu seneki ABD başkanlık seçimlerinin, dijital-elektronik haber kaynaklarını, toplumun en süratli bilgi edinme, haber alma gereksinimi açısından, en büyük noktaya taşıdığı söylenirken, Başkanlık seçimleriyle ilgili haberleri, yüzde 65 sıklıkla elektronik haber kaynaklarından edindiğini, yaklaşık yarısının (yüzde 48) internet haber sitelerinden ve yüzde 44'ünün de sosyal paylaşım ağlarından öğrendiği ve takip ettiği söylenmiştir. 


\subsection{Türkiye'de Habere Erișim Ortamı Olarak Sosyal Medya}

Oxford Üniversitesi'ne bağlı Reuters Enstitüsü’nün 26 ülke için yaptığı Dijital Haber Raporu 2016 başlıklı araştırmasında yer alan verilere göre, Türkiye'de haftalık habere ulaşım kaynağının yüzde 90'ı internet olarak belirlenirken, bunun yüzde 73'ü sosyal medyadan sağlanmaktadır (Dijital Haber Raporu, 2016).

Türkiye, yüzde 73 ile sosyal medyayı haber kaynağı olarak kullanan ilk beş ülke arasına ikinci sıradan girmiştir. Rapora göre sosyal ağların haber kaynağı olarak haftalık kullanımında yüzde 64 ile Facebook birinci sırada yer alırken, ikinci sırayı yüzde 31 ile video paylaşım sitesi olan Youtube almaktadır. Twitter'dan haber okuyanlar ise yüzde 30 ile üçüncü sıradadır. Bu rakamlara göre haber kaynağı olarak Facebook kullanımının diğer platformları ikiye katlayacak bir üstünlükte olduğu görülmektedir.

Raporda Türkiye'de yer alan dijital haber sitelerinin de, haber okunmasında önemli bir araç olduğunun altı çizilmektedir. İnternet ortamında doğan ve haberlerini ajanslardan veya gazetelerden alan Mynet (36\%), InternetHaber (22\%) EnSonHaber (20\%) gibi sitelerin Türkiye'de ana haber kaynağı olarak okunmasında önemli bir dilimi kapsadığı belirtilmektedir.

Bu araştırmada Türkiye'de sosyal medyadan haber alma oranının yüzde 90'a kadar çıkmış olması, araştırmanın metodu ile de ilgili olabilmektedir. Anket yoluyla kullanıcılara sosyal medyadan haber alma eğilimleri sorularak bu yüzde elde edilmiştir. Haber okuma ve haberdar olma dijital gazeteler için farklı sonuçlar doğurmaktadır. Gündem konularını okumadan da başlıklarından takip etme imkanı sağlayan platformlarda kullanıcılar için haber alma olarak yorumlanırken, dijital gazeteler için önemli olan haberin linkine tıklanarak okutulmasıdır. Okunma siteye trafik sağlarken, diğeri sadece haberin bilinmesini en fazla gazetenin adının duyulmasına olanak sağlamaktadır. Yorumlardan, en çok paylaşılan konularından veya paylaşımlarından haberdar olma ya da sadece başlık okuyarak paylaşım yapma alternatifleri, dijital gazeteler için ücretsiz reklam avantajı olarak düşünülebilir.

\section{Araștırma}

İki yönlü sürdürülen bu araştırmada öncelikle seçilen sitelerin sosyal medya hesapları incelenerek sosyal medya stratejileri belirlenmeye çalışılmış, ardından sosyal medya kullanımlarının haber okunurluğuna etkisi araştırılmıştır.

Bu amaçla yapılan araştırmada, dijital gazetelerin 11-17 Mayıs 2016 tarihleri arasında girilen haberleri ve gazetelerin sosyal medya hesapları incelenerek öncelikle iki ana soruya cevap aranmıştır.

1.Dijital gazetelerin sosyal medya stratejileri nelerdir?

2.Dijital gazetelerde sosyal medyanın haber okunurluğuna etkisi nedir? 
Dijital gazetelerin sosyal medya stratejilerini saptamak amacıyla cevaplanan sorular şunlardır:

A. Dijital gazeteler sosyal medyayı nasıl kullanmaktadır?

a. Dijital gazetelerin haberlerini sosyal medyada paylaşım oranı nedir?

b. Dijital gazetelerin sosyal medya paylaşımlarında hangi haber kategorisini öne çıkmaktadır?

c. Dijital gazetelerin haber paylaşımlarında hangi saat diliminde girilen haberleri öne çıkmaktadır?

d. Dijital gazeteler sosyal medyada hangi saat dilimlerinde hangi haber kategorisini daha çok paylaşmayı tercih etmiştir?

B. Dijital gazetelerin sosyal medya platformlarında takipçi sayıları nedir?

Dijital gazetelerde sosyal medyanın haber okunurluğuna etkisini saptamak için cevaplanacak sorular ise şunlardır:

A. dijital gazetelerin belirtilen tarihler arasında haberlerinin okunma sayıları nelerdir?

B. Dijital gazetelerin belirtilen tarihler arasında yayınladıkları haberlere sosyal medyadan gelen okuyucu sayısı nedir?

C. Dijital gazetelerin okunan haberlerine sosyal medyadan gelen okuyucu oranı nedir?

\subsection{Araștırma Evreni ve Örneklem Süreci}

Türkiye'de sadece internet ortamında yayın yapan dijital gazeteler, araştırmanın evrenini oluşturmaktadır. Dijital gazetelerde haber okunurluğuna sosyal medyanın katkısını öğrenebilmek için, haberlerin okunma sayıları ve bu okuyucuların hangi kaynaktan geldiği bilgilerine intiyaç duyulmaktadır. Bu bilgilere, haber siteleri Google Analytics ${ }^{3}$ raporları yardımıyla ulaşabilmektedir. Bu raporlar sitelerin özel Google hesaplarında sunulduğundan; ancak gazetenin izni ile erişim sağlanabilmektedir. Bu nedenle çok sayıda dijital gazeteden Google Analytics raporlarına erişim izni istenmiştir. Olumlu yanıt alınan T24, Rotahaber ve Korhaber olmak üzere üç dijital gazete araştırmanın sınırlıığını oluşturmaktadır. Sosyal ağlar olarak tüm siteler tarafından ortak olarak en fazla kullanılan Facebook ve Twitter hesapları seçilmiştir.

3 Google Analytics, bir internet sitesinin, mobil uygulamanın veya internete bağlı bir cihazın ziyaretçilerinin davranışlarını detaylı raporlayan, belli bir kotaya kadar ücretsiz olan bir Google servisidir. 


\subsection{Veri Toplama Yöntemi}

Araştırma kapsamında veriler iki aşamada toplanmıştır. Illk olarak 11 Mayıs 2016 17 Mayıs 2016 tarihleri arasında T24, Rotahaber ve Korhaber adlı dijital gazetelerin, Facebook ve Twitter hesaplarından yapmış oldukları paylaşımlar kayıt altına alınarak tablolaştırılmıştır. Tablolar yapılırken sitelerin paylaştığı haberlerin adı, saati, kategorisi ile haberlerinin Twitter'da ve Facebook'da paylaşılma sayıları kaydedilmiştir. Haber saatleri bakımından analiz yaparken kolaylık sağlaması açısından 24 saatlik zaman dilimi 4 eşit kuşağa bölünmüştür. (00:00 - 05:59) saatleri arası 0-6 dilimi, (06:00 11:59) saatleri arası 6-12 dilimi, (12:00 - 17:59) saatleri arası 12-18 dilimi, (18:00 23:59) saatleri arası 18-24 dilimi olarak adlandırılmış ve tabloda yeni bir sütun açılarak haberin girildiği saate göre zaman dilimi eklenmiştir.

İkinci aşamada ise, web analiz aracı olan Google Analytics tarafından 11 Mayıs 2016 - 17 Mayıs 2016 tarihleri arasında T24, Rotahaber ve Korhaber sitelerinde yer alan haberlerin okunma sayılarına göre sıralanmış ilk yüz verisi arasından sadece haberlerin okunma sayıları ile bu haberlerin Twitter ve Facebook aracılığıyla gelen okunma sayıları tablolaştırılmıştır. Sosyal medyanın haber okunurluğuna etkisinin tespit edilmesi amaçlandığından bu yüz veri arasından yazarlar ve video-foto galeri vb. haber dışı kategoriler çıkartılmıştır.

Sonuç olarak, haber sitelerinin 11-17 Mayıs 2016 tarihli Google Analytics verileri ve sosyal medya hesaplarından alınan veriler olmak üzere iki aşamada toplanan veriler haber başlıkları altında birleştirilerek büyük bir tablo haline getirilmiştir. Toplamda üç siteden 1.579 internet haberi, 986 tweet ve 647 Facebook paylaşımı kaydedilmiştir. Tüm veriler her bir haber başıı̆ı altında birleştirerek MS Office Excel programındaki bir çalışma tablosuna aktarılmıştır.

\section{Bulgular}

\subsection{Dijital Gazetelerin Sosyal Medya Stratejileri}

Araştırmanın ilk aşamasında dijital gazetelerin Facebook ve Twitter hesaplarını nasıl kullandıklarına bakılmıştır. Bunun için tüm verileri içeren tablodan, gazetelerin haberlerini sosyal medyada ne kadar paylaştıkları, paylaşımlarını yaparken hangi kategorileri veya hangi saat dilimini özellikle seçtikleri, herhangi bir saat diliminde herhangi bir haber kategorisinin öne çıkartılıp çıkartılmadığı gibi soruları cevaplayacak veri analizleri yapılmıştır. Bu analizlerin ardından, sosyal medya stratejileri anlamlandırılmaya çalışılmıştır.

\subsubsection{Sosyal Medya Kullanımları}

Dijital gazeteler, Facebook sitesinde haber paylaşımını iki farklı yöntem ile yapabilmektedirler. İlk yol, haberin linkini kopyalayıp, herhangi bir paylaşım yapmak için girilen hesabın ana sayfasında, 'aklından neler geçiyor' yazısı görülen yere 
yapıştırmak şeklinde uygulanan yöntemdir. Haberin paylaşıldığı resim, haberin başı̆̆ı ve bir özet cümle Facebook tarafından otomatik alınmaktadır. Sitenin haberini paylaşan kişi bu linkin verildiği kısmı silip, istediği yorum, başlık veya etiketleme (hashtag) ile paylaşım yapılabilmektedir.

İkinci yol ise, sitenin içinden Facebook butonu ile sitenin sayfasını seçerek paylaşım yapılmasıdır. Site içindeki haberleri önce Facebook'ta paylaş butonuna, ardından 'Yönettiğin bir sayfada paylaş' linkine tıklayarak sitenin sayfasında paylaşım yapılabilmektedir. Paylaşım sitedeki haberin resmi büyüklüğünde bir resim, haberin başlığı ve bir cümlesi şeklinde olmaktadır. Sitenin haberini paylaşan kişi 'Bunun için bir şeyler yaz' kısmında haberle ilgili yorum, başlık veya etiketleme yapabilir. Buradaki habere tıklandığında takipçiler, haber sitelerinin ilgini sayfasına yönlendirilmektedir.

Dijital gazeteler Twitter'da da haber paylaşımı yaparken iki farklı yöntem kullanabilmektedirler. Illk yöntemde, Twitter'ın 'Neler Oluyor?' yazan yerine önce haberin başlığı, eklenmek istenen yorum veya etiketler yazılarak haberin internet sayfasındaki linki kopyalanıp yapıştırılmaktadır. Paylaşanın isteğine bağlı olarak fotoğraf butonu tıklanarak haberin resmi de eklenebilmektedir. Buradaki linke tıklandığında takipçiler, haber sitelerinin ilgili sayfasına yönlendirilmektedir.

Bir diğer paylaşım yolu da sosyal medya yöneticisinin, sitenin hesabından sitedeki haberlerin altında yer alan 'tweetle' butonu yardımıyla paylaşım yapmasıdır. Bu durumda sosyal medya eklentisinin yazılımına göre paylaşımların şekli değişiklik göstermektedir.

\subsubsection{Sosyal Medyada Paylașım Oranları}

Araştırma kapsamındaki dijital gazetelerin sosyal medyayı ne kadar kullandıklarını anlamak için haberlerini sosyal medyada ne oranda paylaştığı tespit edilmek istenmiştir. Burada göze çarpan ilk ayrıntı, hiçbir haber sitesinin haberlerinin tümünü sosyal mecralarda paylaşmamış olmalarıdır. Diğer göze çarpan ayrıntı ise genellikle Facebook ve Twitter'da farklı oranlarda haber paylaşımında bulunmalarıdır.

Bu oranlarda T24 adlı haber sitesinin Twitter'da \%72 ile birinci sırada olduğu görülürken, Facebook'da ise Korhaber sitesinin haberlerinin \%66'sını paylaşarak birinci sırada olduğu belirlenmiştir. T24 sitesi Facebook'da haberlerinin \%63'ünü paylaşırken, Korhaber sitesi Twitter'da tıpkı Facebook paylaşımlarında olduğu gibi \%66 oranında paylaşım yapmıştır. Rotahaber'in haberlerini paylaşma oranlarına bakıldığında ise Twitter'da \%53, Facebook'da ise sadece \%8 olduğu görülmüştür.

Bu veriler ışığında dijital gazetelerin haber paylaşımında Twitter'ı daha çok kullandığı tespit edilmiştir. Sadece Korhaber adlı dijital gazete Facebook ve Twitter ağlarını aynı oranda kullanmayı tercih etse de, kullanım oranına bakıldığında yine yüzde 66'ı ile azımsanamayacak bir Twitter kullanımı olduğu görülmüştür. 


\subsubsection{Sosyal Medyada Paylaștıkları Haberlerin Kategori Dağılımı}

Sosyal medyayı kullanım oranları belirlenen sitelerin paylaşımlarında ne tür haberleri ön plana çıkarttıklarını anlamak için Twitter ve Facebook'da paylaştıkları haberler kategorileri bazında değerlendirilmiştir. Araştırma kapsamındaki üç dijital gazetenin Twitter' da en çok paylaştığı ilk iki haber kategorisinin 'Güncel' ve 'Siyaset' kategorisi olduğu belirlenmiştir. Sitelerin en çok paylaştığı üçüncü kategorilerde ise farklılıklar olduğu görülmüştür.

Twitter'da Rotahaber üçüncü olarak 'Magazin' kategorisindeki haberleri paylaşmayı tercih ederken T24 sitesi 'Spor', Korhaber sitesi ise 'Ekonomi' kategorisini paylaşmayı seçmiştir.

Üç gazete için de 'Güncel' ve 'Siyaset' kategorilerinin paylaşım yüzdeleri diğer kategorilerden açık ara önde olup, Rotahaber (yüzde 49,5) ve T24 ( yüzde 49), yüzde elliye yakın bir oranda 'Güncel' kategorili haber paylaşmıştır. Korhaber için de yüzde 39,6 oranında haber paylaşımı ile en çok paylaşılan kategori 'Güncel' kategorisi olmuştur.

'Güncel' veya 'Gündem' kategorisinde günün öne çıkan haberleri, yaşanan sıcak gelişmeler, son dakika haberleri gibi gün içinde yaşanan önemli haberler yer almaktadır. 'Siyaset' kategorisinde ise seçimler, milletvekilleri, yasalar vb. hakkında gerçekleşen günlük siyasi haberler bulunmaktadır. Bu kategorilerde paylaşımların diğer kategorilerden fazla olması gazetelerin, gündem yaratma ya da gündem haberlerini güçlendirme çabası olarak yorumlanabilmektedir. Bu iki kategorideki haberler neredeyse başııklarına kadar büyük oranda aynılık göstermektedir. Görüş ayrılığı olacak siyasi durumlarda ise başlıklar ve okuyucuya verme biçimleri değişmiştir. Bununla birlikte üçüncü sıralara bakıldığında aslında sitelerin gündem dışında neyi ön plana çıkardığı, bir başka deyişle haber politikaları hakkında fikir edinilebilmektedir. Rotahaber üçüncü olarak (Güncel kategorisinden yüzde 43,8 farkla) yüzde 5,7 oranında 'Magazin' kategorisini ön plana çıkarırken, T24 sitesi paylaşımlarında (Güncel kategorisinden yüzde 41,3 farkla) yüzde 7,7 oranında 'Spor' kategorisine ağırlık vermiştir. Korhaber sitesi ise yüzde 9,2 ile 'Ekonomi' kategorisine yer vermiştir. Bu oranlardaki farklılık gazetelerin asıl amacının Twitter'da özgün paylaşımlar yaparak takip edilmek yerine, gündem haberleriyle takipçilerine ulaşmak olduğunu bir kere daha vurgulamıştır.

Araştırma kapsamındaki üç dijital gazetenin Facebook'da en çok paylaştığı kategorilere bakıldığında da, Twitter'da olduğu gibi, ilk iki kategorinin 'Güncel' ve 'Siyaset' kategorisi olduğu belirlenmiştir. Haber sitelerinin Facebook'da en çok paylaştığı üçüncü kategorilerin ise, Rotahaber tarafından 'Medya' (yüzde 6,8) , T24 tarafından 'Spor' ve 'Dünya' (yüzde 7,1), Korhaber tarafından ise Ekonomi (yüzde 9,2) kategorisi olduğu belirlenmiştir. Twitter'da olduğu gibi Facebook paylaşımlarında da gazeteler önceliği güncel ve siyasi konulara vererek, gündem yaratmayı veya yaratılan gündeme okuyucu çekmeyi hedeflemişlerdir. Hatta Rotahaber gibi bu platformu haber okutma amacından çok video-resim galeri gibi eğlendirme amaçı kullanan bir site bile paylaştığı haberlerinin yüzde 70'ini bu kategoriden seçmiştir. 


\subsubsection{Sosyal Medyada Paylaștıkları Haberlerin Saat Dilimlerine Göre Dağııımı}

Araştırma kapsamındaki dijital gazetelerin, haberlerin giriş saati baz alınarak, sosyal medyada hangi saat dilimde girilen haberlerini daha çok paylaştığı araştırılmak istenmiştir. Üç site için, 0-6 dilimi ve 18-24 diliminde diğer saatlere göre daha az paylaşım yapıldığı tespit edilmiştir.

Rotahaber ve T24'ün Twitter'da daha çok 6-12 diliminde girdikleri haberleri paylaştıkları görülürken, Korhaber'in ise Twitter'da en çok paylaşımı 12-18 diliminde girdiği haberlerden seçtiği gözlenmiştir.

Coschedule.com'da yer alan Nathan Ellering tarafından 16 çalışmadan derlenerek oluşturulan 'What 16 Studies Say About The Best Times To Post On Social Media' adlı çalışmada Twitter'da paylaşım yapmak için belirlenen en iyi saatler, 12-18 diliminde yer almaktadır. Bu saat diliminde en çok paylaşım yapan Korhaber'in diğer sitelere göre daha az etkileşim alması sosyal medyada etkin olabilmek için, saat dışındaki diğer faktörlerinde etkili olduğunu göstermiştir.

Çalışmada Twitter'ı daha çok kullanıcıların yolda gidip gelirken kullandığı söylense de, elde edilen verilere göre Türkiye'de daha çok iş saatleri içinde kullanıldığı görülmüştür.

Sitelerin Facebook'da en çok paylaşım yaptığı saat dilimine bakıldığında ise T24 dışında, Twitter paylaşımlarından farklı olduğu görülmüştür. T24'ün yine en çok 6-12 diliminde paylaşım yaptığı, Rotahaber'in 12-18 diliminde, Korhaber'in ise 6-12 diliminde en çok paylaşım yaptığı belirlenmiştir.

Coschedule.com'daki 'What 16 Studies Say About The Best Times To Post On Social Media' adlı çalışmada Facebook'da paylaşım yapmak için belirlenen en iyi saatler hafta sonuna doğru ve hafta sonu 13.00-16.00 saatleri aralığı, Çarşamba günü için saat 15.00 olarak belirtilmektedir. Çalışmaya göre, Facebook’ta etkileşim almak için paylaşım yapılması gerekli en iyi 3 saat, sabah 9.00, öğleden sonra 13.00 ve 15.00 saatleridir.

Araştırma verilerinden elde edilen sonuçlara göre Rotahaber, 12-18 dilimindeki haberlerini daha çok paylaşım yaparak Facebook'un etkili olduğu saat dilimini kullanmıştır; ancak burada da Twitter'da olduğu gibi etkin saati kullanmasına karşın Facebook'da haberlerinin sadece yüzde sekizini paylaşan Rotahaber, bu platformu etkin olarak kullanamamıştır. Diğer iki site de, 6-12 dilimi ile paylaşım için uygun olan bir aralıkta paylaşım yapmışlardır.

\subsubsection{Sosyal Medyada Paylașılan Haberlerin Saat Dilimlerine Göre Kategori Dağılımı}

Dijital gazeteler tarafından sosyal medyada paylaşılan haberlerin kategorilere ve saat dilimlerine göre dağılımları ayrı ayrı belirlendikten sonra bu iki değişken birlikte incelenerek siteler bazında, saat dilimlerine göre hangi kategorilerin ön plana çıktığı 
araştırılmıştır. Bu amaçla açık kaynaklı bir istatistik programı olan SOFA STATS programından faydalanılmıştır. Saat dilimlerine göre gruplandırılan veriler ile haber kategorilerine gruplandırılan veriler program yardımıyla çapraz tablolar haline getirilmiştir. Böylece, dijital gazetelerin Twitter ve Facebook'da paylaştıkları haberlerin saat dilimlerine göre kategori dağılımları elde edilmiştir.

Araştırılan üç dijital gazete için elde edilen sonuçlara göre, gazetelerin paylaşımlarında saat dilimlerinin değişikliğinin, paylaşılan haber kategorisine bir etkisi olmadığı belirlenmiştir. Üç gazete de her saat diliminde en çok 'Güncel' kategorili haber paylaşmayı seçmiştir. Bununla birlikte gazetenin saat dilimlerine göre paylaşımlarını farklılaştırmayı seçmediği, bu bağlamda özel bir strateji izlemediği de görülmüştür.

\subsubsection{Sosyal Ağlardaki Takip Edilirliği}

Araştırma kapsamında dijital gazetelerin sosyal medya hesaplarına bakılarak takip edilirliklerini değerlendirmek amacıyla takipçi sayıları kaydedilmiştir.

Seçilen siteler arasında takip edilirliği en fazla olanın 189.512 Facebook takipçisi ve 736.000 Twitter takipçisi ile T24 olduğu görülmüştür. Bu sırayı 113.272 Facebook takipçisi ve 1.028 Twitter takipçisi ile Rotahaber takip etmektedir. Son sırada ise 1.277 Facebook takipçisi ve 1.958 Twitter takipçisi olan Korhaber yer almaktadır.

\subsection{Dijital Gazetelerde Sosyal Medyanın Haber Okunurluğuna Etkisi}

Dijital gazetelerin sosyal medya kullanım stratejilerinin incelenmesinin ardından, haberlerinin okunmasında sosyal medyanın etkisi araştırı ımışır. Bu amaçla sitelerin kendi istatistiki verilerine ulaşılmasını sağlayan Google Analytics verilerinden, haberlerin okunma sayılarına ve bu okuyucuların haberlere hangi kaynaktan geldiği bilgilerine ulaşılmıştır. Araştırma kapsamında sosyal medyanın etkisi incelenmek istendiğinden, haberlere Twitter ve Facebook'tan gelen kullanıcı sayıları kaydedilmiştir.

Tablo 1: Dijital Gazetelerin Haberlerinin Okunmasında Sosyal Medyanın Etkisi

\begin{tabular}{|c|c|c|c|}
\hline & Okunma & $\begin{array}{c}\text { Sosyal Medya'dan Gelen } \\
\text { Okunma }\end{array}$ & $\begin{array}{c}\text { Sosyal Medya } \\
\text { Etkisi (\%) }\end{array}$ \\
\hline Rotahaber & 2.617 .941 & 135.985 & 5,2 \\
\hline T24 & 1.661 .534 & 422.004 & 25,4 \\
\hline Korhaber & 1.168 .861 & 98.921 & 8,5 \\
\hline
\end{tabular}

$\mathrm{Bu}$ veriler ışığında, Rotahaber'in haberlerinin okunmasında sosyal medyanın etkisi yüzde 5,2, Korhaber'in haberlerinin okunmasında sosyal medyanın etkisi yüzde 8,5'dir. T24 sitesinde ise sosyal medya etkisinin yüzde 25,4'e çıktığı görülmektedir. 
Tablo 2: Dijital Gazetelerin Haberlerinin Okunmasında Twitter'ın Etkisi

\begin{tabular}{|l|c|c|c|}
\hline & Okunma & $\begin{array}{c}\text { Twitter'dan Gelen } \\
\text { Okunma }\end{array}$ & $\begin{array}{c}\text { Twitter Etkisi } \\
(\%)\end{array}$ \\
\hline Rotahaber & 2.617 .941 & 106.670 & 4,1 \\
\hline T24 & 1.661 .534 & 200.439 & 12,1 \\
\hline Korhaber & 1.168 .861 & 75.065 & 6,4 \\
\hline
\end{tabular}

Dijital gazetelerin haberlerinin okunmasında Rotahaber'de yüzde 5,2'lik sosyal medya etkisinin yüzde 4,1'inin Twitter'dan geldiği görülmüştür. T24'de yüzde 25,4'lük sosyal medya etkisinin yüzde 12,1'inin Twitter'dan geldiği belirlenmiştir. Korhaber'de ise 8,5'lik sosyal medya etkisinin yüzde 6,4'ünün Twitter'a ait olduğu gözlenmiştir.

Tablo 3: Dijital Gazetelerin Haberlerinin Okunmasında Facebook'un Etkisi

\begin{tabular}{|l|c|c|c|}
\hline & Okunma & $\begin{array}{c}\text { Facebook'dan Gelen } \\
\text { Okunma }\end{array}$ & $\begin{array}{c}\text { Facebook Etkisi } \\
(\%)\end{array}$ \\
\hline Rotahaber & 2.617 .941 & 29.315 & 1,1 \\
\hline T24 & 1.661 .534 & 221.565 & 13,3 \\
\hline Korhaber & 1.168 .861 & 23.856 & 2,0 \\
\hline
\end{tabular}

Dijital gazetelerin haberlerinin okunmasında Rotahaber'de yüzde 5,2'lik sosyal medya etkisinin yüzde 1,1'inin, T24'de ise yüzde 25,4'lük sosyal medya etkisinin yüzde 13,3'ünün Facebook'dan geldiği belirlenmiştir. Korhaber'de ise 8,5 'lik sosyal medya etkisinin yüzde 2'sinin Facebook'a ait olduğu görülmüştür.

\subsubsection{Haber Giriș Saatlerine Göre Okunurluğuna Sosyal Medyanın Etkisi}

Haberlerin giriş saatlerine göre okunmasında sosyal medya etkisinin ne derece değiştiğine bakıldığında, Rotahaber ve T24'de 18-24 diliminde girdikleri haberlere sosyal medyadan daha çok okuyucu geldiği, Korhaber'de ise 12-18 dilimindeki haberlerinin okunmasında sosyal medyadan daha çok okuyucu geldiği tespit edilmiştir. Bu durumda girilen haberlerin Facebook ve Twitter'da sitelerinde en çok paylaşım yaptıkları saat dilimleri ile sosyal medyadan gelen okuyucunun en çok geldiği saat dilimi farklı olduğu gözlenmiştir. 
Tablo 4: Dijital Haber Sitelerinin Haberlerinin Giriş Saatlerine Göre Sosyal Medyanın Etkisi

\begin{tabular}{|l|r|r|r|r|r|r|r|r|r|}
\hline & \multicolumn{4}{|c|}{ Rotahaber } & \multicolumn{3}{c|}{ T24 } & \multicolumn{3}{c|}{ Korhaber } \\
\hline & $\begin{array}{c}\text { Twitter } \\
\text { Etkisi } \\
(\%)\end{array}$ & $\begin{array}{c}\text { Facebook } \\
\text { Etkisi } \\
(\%)\end{array}$ & $\begin{array}{c}\text { Sosyal } \\
\text { Medya } \\
\text { Etkisi }(\%)\end{array}$ & $\begin{array}{c}\text { Twitter } \\
\text { Etkisi } \\
(\%)\end{array}$ & $\begin{array}{c}\text { Facebook } \\
\text { Etkisi } \\
(\%)\end{array}$ & $\begin{array}{c}\text { Sosyal } \\
\text { Medya } \\
\text { Etkisi }(\%)\end{array}$ & $\begin{array}{c}\text { Twitter } \\
\text { Etkisi } \\
(\%)\end{array}$ & $\begin{array}{c}\text { Facebook } \\
\text { Etkisi } \\
(\%)\end{array}$ & $\begin{array}{c}\text { Sosyal } \\
\text { Medya } \\
\text { Etkisi (\%) }\end{array}$ \\
\hline $0-6$ dilimi & 5,5 & 0,4 & 5,9 & 9,3 & 12,8 & 22,2 & 6,0 & 1,9 & 7,9 \\
\hline 6-12 dilimi & 3,9 & 1,0 & 4,9 & 11,6 & 9,6 & 21,2 & 6,6 & 1,9 & 8,5 \\
\hline $12-18$ dilimi & 3,7 & 1,2 & 5,0 & 13,2 & 11,4 & 24,6 & 6,6 & 2,3 & 8,9 \\
\hline 18-24 dilimi & 4,8 & 1,3 & 6,1 & 13,4 & 21,1 & 34,5 & 6,0 & 2,0 & 8,0 \\
\hline Toplam & 4,1 & 1,1 & 5,2 & 12,1 & 13,3 & 25,4 & 6,4 & 2,1 & 8,5 \\
\hline
\end{tabular}

Dijital gazetelerin haberlerinin giriş saatlerine göre okunmasında Twitter'dan gelen okuyucu sayılarına bakıldığında, Rotahaber ve T24'ün en çok 18-24 diliminde girdikleri haberlere, Korhaber'in ise en çok 12-18 diliminde girilen haberlerine Twitter'dan okuyucu geldiği tespit edilmiştir.

Dijital gazetelerin haberlerinin giriş saatlerine göre Facebook'dan gelen okuyucu sayılarına bakıldığında, Twitter'da olduğu gibi Rotahaber ve T24'ün en çok 18-24 diliminde girdikleri haberlere okuyucu aldığı, Korhaber'in ise en çok 12-18 diliminde girdikleri haberler için okuyucu aldığı tespit edilmiştir.

\subsubsection{Paylașılan Haberlerin Kategorilerine Göre Okunurluğuna Sosyal Medyanın Etkisi}

Araştırmaya haberlerin okunmasında sosyal medya etkisinin haberlerin türüne göre değişiklik gösterip göstermediğini anlamak için, sosyal medya etkisi kategoriler bazında incelenerek devam edilmiştir.

Sitelerin haberlerinin okunmasında sosyal medya etkisinin en çok olduğu kategorilere bakıldığında üç site için farklı sonuçlar elde edildiği görülmüştür. Rotahaber'de en çok 'Sağlık' (yüzde 10,8) kategorisine sosyal medyadan okuyucu geldiği tespit edilmiştir. T24'de 'Dünya' (yüzde 50,3) kategorisindeki haberlere sosyal medyadan gelen okuyucu sayısı en fazla iken, Korhaber'de ise 'Güncel' (yüzde 9,7) kategorisindeki haberlere gelen okuyucunun en fazla olduğu tespit edilmiştir.

Bu sonuçlar değerlendirildiğinde, sitelerin en çok paylaşım yaptığı kategorilerden farklı olduğu gözlenmiştir. Daha önceki bölümlerde ‘Güncel' ve 'Siyaset' kategorileri ön plana çıkarken, haber okunurluğunda sosyal medya etkisine bakıldığında herhangi bir kategorinin ön plana çıkmadığı görülmüştür.

Sitelerin haberlerinin okunmasında Twitter'ın etkisinin en çok olduğu kategorilere bakıldığında ise, Rotahaber'e Twitter'dan en çok 'Spor' kategorisindeki haberlere okuyucu geldiği görülmüştür. T24'de de 'Spor' kategorisindeki haberlere Twitter'dan gelen okuyucu sayısı en fazla iken, Korhaber'de 'Güncel' kategorisindeki haberlerin okunmasına Twitter etkisinin en çok olduğu tespit edilmiştir. 
Dijital gazeteler tarafından paylaşılan haberlerin okunmasında Facebook'un etkisinin haberlerin türüne göre değişiklik gösterip göstermediğini anlamak için, bu etki de kategoriler bazında incelenmiştir.

Sonuçlara göre Rotahaber'e Facebook'dan en çok 'Sağlık' kategorisindeki haberlere okuyucu gelmiştir. T24'de 'Dünya' kategorisindeki haberlere Facebook'dan gelen okuyucu sayısı en fazla iken, Korhaber'de 'Güncel' kategorisindeki haberlerin okunmasına Facebook etkisinin en çok olduğu tespit edilmiştir.

\subsubsection{Haberlerinin Okunmasında Sosyal Medya Etkilerinin Saat Dilimlerine Göre Kategori Dağıımı}

Dijital gazeteler tarafından paylaşılan haberlerin okunmasında kategorilerine göre sosyal medyanın etkisi ve haberlerin giriş saatlerine göre sosyal medyanın etkisi ayrı ayrı incelendikten sonra sosyal medyadan hangi saat diliminde girilen habere hangi kategoriden okuyucu geldiğini öğrenmek için bu iki faktör bir arada incelenmiştir. Yapılan çapraz karşılaştırmalar sonucunda her üç dijital gazete için de tüm saat dilimlerinde, sosyal medyadan en çok Güncel kategorili haberlere okuyucu geldiği tespit edilmiştir.

\section{Sonuç}

Dijital gazetelerin sosyal medyaya entegre olma çabası yadsınamaz bir gerçektir. Her dijital gazetenin kendisine ait birçok sosyal medya platformunda hesapları bulunmakta ve hepsi bu ağları aktif olarak kullanmaktadır. Gazeteler, sosyal ağlardaki kullanıcıyı çekmek için sitelerinde özel paylaşım formatlarına yer vererek, haberlerinin bu platformlarda paylaşılmasını kolaylaştırmaktadır. Bu formatlarla takipçilerine paylaştıkları haberlerini okutmalarının yanı sıra, kendi sosyal medya hesaplarında paylaşmadıkları haberlerin yayılımına veya kendi takipçilerinden olmayan kullanıcılara ulaşmayı hedeflemektedirler.

Gazetelerin sosyal medya kullanımları incelendiğinde, paylaşım yaparken tüm haberlerini kullanmadıkları; daha çok gündem haberlerini paylaşmayı tercih ettikleri gözlenmiştir. Paylaşımlarında asıl amacın, haber okutmaktan çok, sitenin trafiğini arttırmak ve oluşturulan gündem haberlerini güçlendirmek olduğu belirlenmiştir. Bu nedenle haberlerden daha fazla olacak şekilde, video-foto galeri ve sevilen yazarların köşe yazılarını paylaşma yoluna gittikleri görülmüştür. Bununla birlikte dikkat çeken gündeme dair haberleri yine farklı saatlerde birden fazla paylaşarak, sosyal medyanın akış sıralamalarında farklı saatlerde yer alarak daha çok tıklanmayı hedefledikleri görülmüştür.

Dijital gazeteler paylaşımlarını genel olarak en çok çalışma saatlerini içine alan saat dilimlerinde yapmaktadır. Gazetelerin paylaşımlarında ve aldığı takipçi etkileşimlerinde saat dilimleri değişikliğinin, okunan haber türüne bir etkisi olmadığından, gazeteler saat dilimlerine göre paylaşımlarında özel bir strateji uygulamamaktadır. 
Dijital gazeteler sosyal ağlardaki haber paylaşımlarında, haberlerini görsellerle desteklemektedir. Paylaşımlarda daha çok sitelerde yer alan haberin resminin kullanılmasıyla birlikte, yazıyla desteklenen görseller de tercih edilmektedir.

Dijital gazetelerin sosyal ağlardaki takipçi sayılarının fazla olması o ağdan etkin bir şekilde yararlandıkları ya da trafik aldıkları anlamına gelmemektedir. Bunun yanında her takipçinin tıklanma sayısını arttıracağını düşünerek, gazeteler takipçi sayılarını arttırma çabasındadır. Sosyal medya ağlarının reklam alternatifleri de takipçi sayılarının artması ve haberlerin okunmasında yardımcı kaynak olmaktadır. Sponsorlu haber alternatifi ile birlikte, gazetelerin seçtiği haberlerin takipçileri olmayan kişilerin sayfalarında görünmesi, haberlerinin okunması ve gazetenin bilinirliğinin artmasına olanak sağlanmaktadır. Gazetelerin doğrudan kendi sayfalarının veya profillerinin tanıtımını yaparak takipçi sayılarını artırma olanakları da bulunmaktadır.

Dijital gazeteler takipçi sayısını arttırma hedeflerinde ortaklaşsalar da, sosyal medyanın farklılıklarını ve yeniliklerini kullanmadıkları görülmüştür. Okuyucu yorumlarına kendi sitelerinde yer veren gazeteler, sosyal medya ortamlarında hiçbir kullanıcı yorumuna yer vermeyip, bunlara cevap verme, paylaşma, taleplerini karşılama vb. okuyucunun aktif olarak katılabileceği ortamlar yaratmamaktadır. Bu durumda kullanıcı yorumlarının, yazılı basında gazeteye gönderilen mektuplardan farklı bir anlamı yoktur. Sadece yorum yapabilmenin kolaylaştığı platformlarda, dijital gazeteler aktif gibi görünen pasif kullanıcılar yaratmıştır.

Bir sosyal medya yeniliği olan etiket (\#hashtag) kullanımına yer vermeden sadece haber ve link paylaşmaları, dijital gazeteleri sosyal ağlarda bir adım geriye düşürmektedir. Konu bazında insanları ortak paydada buluşturan etiketler, hem insanların ilgilendiği habere kısa yolla ulaşılmasını hem de tartışılan bir konuda gazetenin haberini de içine alarak aslında yine tıklanma hedefine iyi bir hizmet sunmaktadır. Dijital gazetelerin paylaşımlarında sadece link veya buton kullanması, kolay yolu tercih ettikleri veya sosyal medya hesaplarını aktif olarak kullanma konusunda tam olarak bilgi sahibi olmadıkları şeklinde yorumlanabilir.

Facebook ve Twitter olarak incelenen iki ağda, aynı haberlere farklı tepkiler verilebildiği gibi, sitelerin bu ağlarda farklı haberleri ön plana çıkarttıkları görülmüştür. Bir haber Twitter'da paylaşım rekorları kırıp yorum yağmuruna tutulurken, Facebook'da bir paylaşım bile almadığı görülmüştür. Bu durum hem ağların kullanıcı profillerinin farklılığı, hem de dijital gazetelerin bu ağları farklı kullanmasından kaynaklanabilmektedir. Dijital gazeteler haber dağıtımında Twitter'ı daha etkili kullanırken, eğlenceli video-foto galeri veya yazar paylaşımlarında genellikle Facebook 'u kullanmayı tercih etmektedir.

Sonuç olarak, dijital gazeteler özgün paylaşımlarla sosyal medya ortamında olmaktan çok, bu ağlarda sadece sıradan içerik paylaşma yöntemiyle haber paylaşmayı tercih etmektedir. Artan sosyal medya kullanım rakamları dikkate alındığında, ciddi bir okuyucu potansiyeline sahip olan bu ağlar, düzgün stratejiler ve değişen gazetecilik anlayışıyla yenilendiğinde dijital gazetelerin okuyucu getirme ve tıklanma amacını 
gerçekleştirme potansiyeli büyük platformlardır. Bu nedenle sosyal medyada dijital gazetelerin varlığı ayrı bir iş kolu olarak görülüp, uzmanları tarafından etkin bir şekilde yönetilirse dijital gazetelere katkısının daha fazla olacağı düşünülmektedir.

Bu kullanım şartları altında sosyal medyanın dijital gazetelerdeki haber okunurluğuna etkisi araştırıldığında her gazeteye ait farklı yüzdeler elde edilmektedir. Sosyal medyadan gelen okuyucu sayısı, hem gazeteler bazında, hem de haberlerin içeriği ve giriş saatlerine göre değişiklik göstermektedir. Bunun sonucunda her gazete için belli bir oranda etkisi olduğu ancak bu etkinin beklenenden az olduğu söylenebilir. Bu konuda yapılan uluslararası çalışmalarda daha net ve yüksek sonuçlar elde edilmiştir.

Bununla birlikte, Columbia Üniversitesi ve Fransız Ulusal Enstitüsü tarafından yapılan ve sosyal medya platformlarındaki paylaşım alışkanlıklarını inceleyen araştırmada da (New Study Highlights Power of Crowd to Transmit News on Twitter, 2016) dikkat çekildiği gibi, sosyal medyada binlerce kez paylaşılan linklerin yarısından fazlasının kullanıcılar tarafından tıklanmadan paylaşılması, dijital gazeteler için sosyal medyanın etkisini zayıflatan bir etmendir. İnsanlar sadece paylaşımlarda görünen haberin özetini okuyarak, siteye gitmeden paylaşımda bulunmaktadır.

Sosyal medyanın dijital gazetelerde haber okunmasına etkisi üzerine bir genelleme yaparken, konu veya gündemdeki hassasiyetleri barındıran istisnaları da atlamamak gerekir. Maneviyat yüklü olaylar, olağan dışı gündemler vb. konular bir anda bütün trafikleri altüst edebilmektedir.

Sosyal medya ve haberlerin okunmasına katkısı ile ilgili birçok araştırma sosyal medyanın etkisinin giderek arttığını vurgulamaktadır. Türkiye'deki dijital gazeteler için yapılan bu araştırma sonucunda, T24 sitesi için yüzde 4' lük bir fark ile Facebook'dan daha çok okuyucu geldiği görülse de, diğer sitelere bakıldığında Twitter' ın okunmaya etkisinin daha yoğun olduğu görülmektedir. Bu durum iki sosyal ağın farklı kullanıcı profillerine sahip olmasından kaynaklanabileceği gibi, haber sitelerinin bu iki ağda farklı tarzda paylaşımlar yapmayı tercih etmelerinden de kaynaklanabilmektedir.

\section{Kaynakça}

Beckett, Charlie (2008). Super Media-saving journalism so it can save the World. West Sussex: Blackwell Publishing.

Blackshaw, Peter ve Nazzaro, Michael (2004). Consumer-Generated Media (CGM) 101: Wordof-mouth in the age of the Webfortified consumer. www.nielsenbuzzmetrics.com/whitepapers . Erişim tarihi: 25.01.2017.

Coschedule.com (2016). What 16 Studies Say About The Best Times To Post On Social Media. http://coschedule.com/blog/best-times-to-post-on-social-media/\#twitter . Erişim tarihi: 04.04.2017.

Çakır, Aslı (2009). Yeni İletişim Ortamlarıyla Değişen Gazeteler ve Gazetecilik Anlayışı. Yayınlanmamış Yüksek Lisans Tezi. İstanbul: Marmara Üniversitesi SBE. 
Dijital Haber Raporu 2016. http://www.digitalnewsreport.org/survey/2016/turkey-2016/. Erişim tarihi: 09.01.2017.

Does Twitter Matter for News Sites? (Jan-March 2016). https://www.parsely.com/resources/ authority-report-10/ .Erişim tarihi: 08.02.2017.

İnternet ve Sosyal Medya Kullanıcı İstatistikleri (2017). http://www.dijitalajanslar.com/internet-vesosyal-medya-kullanici-istatistikleri-2017/ . Erişim tarihi: 08.02.2017.

Kalsın, Berrin (2016). Geçmişten Geleceğe İnternet Gazeteciliği: Türkiye Örneği. The Journal of Academic Social Science Studies Jasss, Number: 42, p. 75-94, Winterlll, http://www.jasstudies. com/Makaleler/1469789531_6.\%20Yrd.\%20Do\%C3\%A7.\%20Dr.\%20Berrin\%20KALSIN.pdf Erişim tarihi: 18.04.2017.

Kaplan, Andreas M. ve Haenlein, Michael (2010). Users of the world, unite! The challenges and opportunities of Social Media. Business Horizons (53), 59-68.

Kırçı, Aslı Güngör ve Karagüler Turhan (2003). Dijital Çağda İletişime Yeni Yaklaşım: Online Gazetecilik, Akademik Bilişim Konferansı. Adana: Çukurova Üniversitesi

Kurt, Hanifi (2014). Gazetecilik Pratiği ve Sosyal Medya. Gaziantep University Journal of Social Sciences, sayı:13(4), s:821-835. http://dergipark.gov.tr/download/article-file/223557 . Erişim tarihi: 18.04.2017.

Mangold W.Glynn ve Faulds David J. (2009). Social media: The new hybrid element of the promotion mix, Business Horizons, (52),357-365.

New Study Highlights Power of Crowd to Transmit News on Twitter (2016). Columbia University. http://datascience.columbia.edu/new-study-highlights-power-crowd-transmit-news-twitter

Erişim tarihi: 06.03.2017

Pavlik, John V. (2013). Yeni Medya ve Gazetecilik. Phoenix:Ankara.

Pew Resarch Center (2016). State of the News Media. http://www.pewresearch.org/topics/stateof-the-news-media/. Erişim tarihi: 18.04.2017.

Rudin, Richard ve Ibbotson, Trevor (2003). An Introduction to Journalism, Essential Techniques and Background Knowledge. Oxford: Focal Press.

Safko, Lon (2010). The Social Media Bible. New Jersey: John Wiley and Sons.

Sosyal Medyada Haberler Okunmadan Paylaşılıyor (2017). Aljazeera.http://www.aljazeera.com. tr/haber/arastirma-sosyal-medyada-haberler-okunmadan-paylasiliyor . Erişim tarihi: 06.03.2017.

Top 15 Most Popular News Websites (2016). eBizMBA. http://www.ebizmba.com/articles/newswebsites. Erişim tarihi: 17.12.2016.

Toruk, İbrahim (2008). Gutenberg'den Dijital Çağa Gazetecilik Türkiye'de Haber Siteleri. İstanbul: Literatürk.

Türkiye'de mobil kullanıcı araşıırmasının sonuçlarını yayımlıyoruz (2016). https://webrazzi. com/2016/05/11/turkiyede-mobil-kullanici-arastirmasinin sonuclarini-yayimliyoruz-ozel-haber/ Erişim tarihi: 14.12 .2016 . 
Akdeniz Iletișim Dergisi

Ilke Atik Tașkiran

Twitter, www.twitter.com.

Understanding Traffic Patrterns from the Top News Topics of 2015 (2015). https://www.parsely. com/resources/authority-report-9/ .Erişim tarihi: 08.02.2017.

Yüksel, Okan (2014). İnternet Gazeteciliği ve Blog Yazarlığı. Ankara: Sinemis Yayınları. 